\title{
EPISTEMIC OBJECTIVITY AND THE VIRTUES
}

\begin{abstract}
The aim of this paper is to bring the resources of virtue epistemology to bear on the issue of the epistemic objectivity of science. A distinction is made between theoretical virtues, which may be possessed by scientific theories, and epistemic virtues, which may be exercised by individual scientists. A distinction is then made between ontological objectivity, objectivity of truth, and epistemic objectivity, the last being the principal focus of the paper. It is then noted that a role must be played by deliberative judgement in determining how to apply the theoretical virtues. It is suggested that such judgement may be virtuous in light of the exercise of the epistemic virtues. It is argued that the primary location of epistemic objectivity is the theoretical virtues, whereas the epistemic virtues of scientists play a subordinate role.

Keywords: objectivity, theoretical virtue, empirical virtue, virtue epistemology
\end{abstract}

Recent work on the theoretical and epistemic virtues is of relevance to the nature of objectivity. A scientist who accepts a theory that satisfies appropriate theoretical virtues has an objective basis for acceptance of the theory. The objective basis of the scientist's theory acceptance may be further enhanced if it arises from the exercise of appropriate epistemic virtues on the part of the scientist. But what is the relationship between the theoretical virtues possessed by the theory and the epistemic virtues exercised by the scientist? And how exactly does either kind of virtue give rise to objectivity?

In this paper, my aim is to bring the recent discussion of theoretical and epistemic virtues to bear on the issue of objectivity. On my view, the primary basis of epistemic objectivity is the theoretical virtues that inform scientists' choice of theory. Provided that the theoretical virtues satisfied by a theory are in fact genuinely truth-conducive norms of inquiry, acceptance by a scientist

* School of Historical and Philosophical Studies, University of Melbourne, Victoria 3010, Australia, e-mail: chs@unimelb.edu.au, ORCID: https://orcid.org/oooo-ooo2-5168-150X. 
of that theory has an objective basis. There is, however, a plurality of theoretical virtues. Scientists must therefore employ their capacity for deliberative judgement in determining the relevance and comparative significance of applicable theoretical virtues. In the course of such deliberative judgement, a scientist may exercise a range of epistemic virtues. The question that I wish to pursue in this paper is that of the relationship between the epistemic virtues exercised in scientific judgement and the objectivity provided by the theoretical virtues.

In outline, the structure of the paper is as follows. In section 1, I discuss the nature and role of the theoretical virtues. In section 2, I draw on recent discussion of Pierre Duhem to characterize the epistemic virtues, and then briefly contrast two major approaches within virtue epistemology. In section 3, I distinguish epistemic objectivity from ontological objectivity and the objectivity of truth, and sketch my preferred account of epistemic objectivity. In section 4, I describe the role played by deliberative judgement due to the multiplicity of theoretical virtues and the possible underdetermination of theory by data. In section 5 , I suggest that, to reduce the risk of subjective factors affecting theory-choice, the epistemic virtues may provide constraint on scientific judgement. In section 6 , I argue that the role played by the epistemic virtues with respect to objectivity is secondary to that played by the theoretical virtues. I conclude by summarizing the discussion and raising questions to be pursued in further development of the present approach.

\section{THEORETICAL VIRTUES}

Theoretical virtues are virtues of theories. They are properties that a theory may possess in terms of which the theory may be evaluated. A good theory is one that satisfies theoretical virtues. A bad theory is one that fails to satisfy the virtues. A number of different theoretical virtues have been identified. Some virtues are primarily empirical, such as fit with available data, predictive accuracy, and explanatory power or breadth. Some are more formal, such as simplicity, coherence, or internal consistency. Others, such as beauty and elegance, seem to reflect aesthetic considerations. Still others, such as practical control and social utility, seem to be broadly pragmatic factors.

The expression "theoretical virtue" is not the only form of words that has been employed to refer to such normative criteria. They are also referred to, inter alia, as criteria of theory-choice, scientific values, and methodological rules or standards. As our focus here is on the virtues that play a role in the evaluation of theories, I will tend to speak of theoretical virtues, though 
another form of words will on occasion be employed where appropriate. My focus on the theoretical virtues should not be taken to suggest that the use of normative criteria in science is restricted to criteria that are employed in the evaluation of theories. Normative criteria are employed at all levels of scientific activity. Principles of experimental design are employed in planning experiments as well as in determining the number and variety of experiments that are to be undertaken. Procedural rules govern the proper use of instrumentation in laboratory and field settings. Due to the idiosyncrasies of particular items of equipment and circumstances of use, there may even be norms of practice that apply to specific items of equipment in specific laboratory or field settings. Moreover, some of the norms employed in science may be tacit rather than explicitly formulated. But, for present purposes, we will focus on the theoretical virtues that form the basis of scientific theory-appraisal.

The theoretical virtues pick out a number of different properties of theories. This has led philosophers to distinguish between different kinds of theoretical virtues. Apart from empirical virtues such as empirical fit and explanatory power, Ernan McMullin (2008: 501-505) distinguishes "internal virtues" such as internal consistency and simplicity, "contextual virtues" such as consonance with theories in surrounding fields, and "diachronic virtues" such as fertility and unification. Heather Douglas (2013: 799-800) distinguishes between minimal criteria and ideal desiderata, as well as criteria or desiderata which apply either to a theory by itself in isolation from evidence or to a theory in relation to evidence. Consistency is a minimal criterion, which applies to a theory by itself. Empirical adequacy with respect to existing - as opposed to all possible - data is a minimal criterion that applies to a theory in relation to evidence. Simplicity is a desideratum that applies to a theory on its own. Unification is a desideratum that applies to a theory in relation to evidence. Approaching the issue in strictly empiricist terms, Bas van Fraassen (1980: 88) distinguishes empirical virtues from pragmatic virtues, which he takes to serve no epistemic role. For his part, Larry Laudan (2004) distinguishes strictly epistemic virtues relating to truth from cognitive virtues such as breadth, scope, and unification.

For our present purposes, it suffices to work with a broad distinction between virtues that are primarily empirical, such as empirical fit and explanatory power, and virtues that are less empirical, such as simplicity and unification. I will sometimes refer to the former as empirical virtues and the latter as non-empirical virtues, though it must be understood that the distinction between empirical and non-empirical virtues is not a sharp one.

It is widely accepted that there are multiple theoretical virtues. This raises the question of the relationship between the virtues. Science is a largely em- 
pirical endeavour. To the extent that this is the case, the more empirical virtues such as empirical fit take precedence over less empirical virtues such as simplicity. But observation is fallible, and more than one theory may fit the known facts. The empirical virtues are therefore not sacrosanct. They may require supplementation by non-empirical considerations. In some cases, they may even need to be over-ridden by non-empirical considerations. But, while the need to grant priority to empirical considerations is widely recognized, it seems also to be widely acknowledged that the theoretical virtues are not regimented into a fixed hierarchical structure. There is no universally agreed or accepted system of ranking which organizes the virtues into a fixed order of precedence. ${ }^{1}$

Because the theoretical virtues do not fall into an established or agreed rank ordering, scientists must determine which theoretical virtues are the most important or relevant in any particular case. This requires that an act or process of deliberative judgement be undertaken on the part of scientists. Insofar as scientists must exercise their own individual judgement in ranking and applying the virtues, it may seem inevitable that subjective elements enter into the scientific decision-making process. But this is not necessarily the case. The epistemic virtues of individual scientists that are activated in the decision-making process may inject an added element of objectivity into the decision. Or, at least, that is what I wish to suggest in this paper. Let us now turn to the topic of epistemic virtue. ${ }^{2}$

\section{EPISTEMIC VIRTUE}

As we saw in the previous section, the theoretical virtues are virtues of theories. They are properties that theories possess. By contrast, the epistemic virtues are properties of individual human subjects. Of particular relevance

\footnotetext{
${ }^{1}$ Douglas's (2013) distinction between minimal criteria and ideal desiderata has the effect of separating the virtues into those that a theory must minimally satisfy and others that a theory ideally would satisfy. This does introduce some regimentation into the virtues. While this significantly reduces the potential for conflict between the virtues, it does not provide an exhaustive rank ordering of them.

${ }^{2}$ I write here of the judgement of an individual scientist rather than the judgment of a group of scientists or the scientific community. The possibility of group-based scientific decision-making raises additional issues of relevance to the objectivity of science. But my focus for present purposes is on the relationship between the theoretical virtues and the epistemic virtues of individual scientists. I set the issue of collective or group-based decision-making to one side for the purposes of the present discussion.
} 
here, they are properties possessed by individual scientists. The epistemic virtues include properties such as intellectual humility and honesty, evenhandedness and open-mindedness. The epistemic virtues are properties, capacities, or skills of a cognitive or intellectual nature that an individual scientist may possess and which they may exercise in the course of deliberative judgement and decision-making. 3

According to virtue epistemology, the epistemic virtues play a pivotal role in epistemic justification and knowledge. In recent years, virtue epistemology has been brought into dialogue with the philosophy of science in connection with the work of Pierre Duhem. David Stump (2007) suggests that light may be shed on Duhem's notion of good sense by analyzing it in virtue-theoretic terms. For Duhem, scientists employ the faculty of good sense to choose between theories even though the empirical evidence may not conclusively favour one theory over the other. Indeed, as Milena Ivanova (2010: 60) notes, appeal to additional non-empirical criteria (e.g., scope, number of hypotheses, novelty of prediction) need not uniquely determine the choice between empirically equivalent theories. As a result, scientists must be guided by good sense in making a decision that is dictated neither by empirical data nor by non-empirical criteria.

Stump points out that Duhem's idea of good sense has both moral and intellectual elements. A scientist who exercises good sense in choosing between theories is like a fair and impartial judge who arrives at a legal decision in a balanced and unbiased manner. The exercise of good sense is not a matter of applying or following a set of clear-cut methodological rules that dictate a unique outcome. Rather, good sense is employed to make a decision whose outcome is not - and is unable to be - determined by rules of method. On Stump's analysis, the scientist's exercise of good sense exemplifies such virtues as fairness and impartiality. These virtues have both a moral and an intellectual dimension. Scientific good sense is not, therefore, a simple faculty. It is one that involves the use and display of a range of virtues that promote sound judgement.

It is customary to distinguish between two broad forms of virtue epistemology (Axtell 1997). On the one hand, the virtue-reliabilist takes there to be cognitive competences whose use reliably leads to truth. On the other hand, the virtue-responsibilist takes there to be character traits constitutive of vir-

\footnotetext{
${ }^{3}$ As with the term "theoretical virtue," there is some variation in usage with respect to the epistemic virtues. Indeed, some authors use the term "epistemic virtue" to refer to the theoretical virtues, especially in the context of realism (e.g., Tulodziecki 2014). What I refer to by the expression "epistemic virtue" are the intellectual or cognitive virtues of individual scientists.
} 
tuous epistemic character. Virtue-reliabilists tend to focus on inbuilt capacities such as perception or memory. Virtue-responsibilists tend to focus on traits such as humility or open-mindedness, which may be acquired and cultivated. Virtue-reliabilism reflects the externalist tendency of earlier forms of reliabilism, whereas virtue-responsibilism aligns more closely with an internalist view of justification. The contrast between reliabilist and responsibilist forms of virtue epistemology can be made intuitively clear. But there is room to doubt that the distinction may be sustained. A fully developed virtue epistemology may require both inbuilt competences and acquired character traits. For our purposes, however, it is not necessary to take a stand on this. Our purpose here is simply to explore the extent to which epistemic virtues may be of assistance with respect to the nature of objectivity. ${ }_{4}$

\section{EPISTEMIC OBJECTIVITY}

The notion of objectivity is widely recognized to be ambiguous (e.g., Douglas 2004). It is useful to distinguish between three basic forms of objectivity. The first form of objectivity is an ontological form of objectivity. There is an objective reality that exists in its own right. The way that objective reality is does not depend on human mental activity such as belief, experience, or language use. The second form of objectivity relates to truth. Truth is objective in the sense that it does not depend on what we believe. It depends on the way things stand in objective reality rather than the way we think that reality is. The third form is epistemic objectivity. In relation to science, this form of objectivity is connected with the idea of a scientific method. Use of the method (or methods) of science excludes subjective factors in favour of epistemic considerations. The relationship between the three forms of objectivity is broadly this: objective truths are made true by the way reality objectively is and use of objective methods leads to discovery of objective truth about objective reality.

\footnotetext{
${ }^{4}$ It is worth noting, however, that the distinction between virtue-reliabilism and virtue-responsibilism may be of relevance to the virtue-theoretic interpretation of Duhem. Ivanova (2010) argues that Stump's virtue-theoretic interpretation of Duhem is unsuccessful insofar as it fails to come to grips with Duhem's anti-realist conception of the aim of science. In his criticism of Ivanova, Kidd (2011) argues that Ivanova fails to take into account the contrast between virtue-reliabilism and virtue-responsibilism, and that Duhem is more appropriately seen in virtue-responsibilist rather than virtue-reliabilist terms. In her response, Ivanova (2011) raises concerns with respect to the case that Kidd makes for the virtue-responsibilist reading of Duhem.
} 
In this paper, the form of objectivity of principal interest is epistemic objectivity. As indicated, this form of objectivity is intimately related to the idea of a scientific method. On a traditional approach to the philosophy of science, science is characterized by the use of a special method, which provides a basis for the demarcation between science and non-science. Use of the method by scientists eliminates the influence of subjective factors such as bias, personal interest, or political orientation from the outputs of science. The method ensures that the only considerations taken into account in scientific inquiry are epistemically relevant factors such as empirical evidence, which contribute to the advance of scientific knowledge. Because of the objective nature of scientific inquiry, science is characterized by widespread consensus. Occasional disagreement among scientists is resolved by means of the shared method. It is precisely because of the objectivity of the methods of science that scientific inquiry generates agreement amongst a range of practitioners. By adopting objective methods that remove subjective elements, science not only promotes knowledge but also ensures consensus.

On a traditional approach to the philosophy of science, science is characterized by a unique method shared throughout the sciences and the history of science. However, since the "historical turn" in the philosophy of science the idea of a single invariant method has fallen out of favour. ${ }^{5}$ On a more contemporary approach, the methodology of science consists of a range of methodological norms and procedures, which is subject to variation between the sciences and across the history of science. In this context, the theoretical virtues discussed in section 1 are to be thought of as methodological norms employed in the evaluation of scientific theories. The theoretical virtues do not exhaust the methodology of science. For, in addition to theory development and appraisal, science involves a range of laboratory-based activities relating to experiment, as well as fieldwork, among other activities. Nor need the set of theoretical virtues be entirely fixed, since some allowance may be made for variation between sciences and across the history of science.

I have elsewhere distinguished between a minimal and a robust sense of epistemic objectivity (Sankey, forthcoming). ${ }^{6}$ In the minimal sense of objectivity, the methodological norms of science, such as the theoretical virtues, have an independence from individual scientists. The theoretical virtues lie

\footnotetext{
5 By the "historical turn," I refer to the shift that took place in the 1960 s following the work of such authors as Thomas S. Kuhn and Paul Feyerabend to a more historically informed and less methodologically orientated approach to the philosophy of science.

${ }^{6}$ I introduce the distinction in connection with Kuhn's account of the scientific values that form the shared basis of theory-choice. Kuhn's values provide a minimal rather than a robust sense of objectivity because no epistemological grounding is provided for the values.
} 
outside the mind of the individual scientist. They reflect features of theories that theories possess that are independent of the scientist. Because the virtues are independent, and reflect real features of theories, there is a sense in which the virtues are objective. Because of their independence, they may play a neutral role in theory-appraisal. But this is a minimal sense of objectivity. Nothing has been said to show that there is a substantive connection of the virtues with truth, or, indeed, with epistemic justification. Without an epistemological grounding for the virtues that explains their relation to truth, the objectivity provided by the virtues is a minimal sense of objectivity. Indeed, with no substantive connection made between the virtues, truth, and justification, it barely qualifies as an epistemic sense of objectivity.

By contrast with the minimal sense, the robust sense of epistemic objectivity requires more than the mere independence of theoretical virtues. At the very least, an account must be provided of the epistemic role played by the virtues with regard to justification and truth. It is not enough that the virtues lie outside the mind of the scientist or that they are able to play a neutral role due to their independence. To be able to play a genuinely epistemic role, use of a theoretical virtue must lead to or, at least, toward the truth. A substantive account must be able to be provided of the epistemic role of the virtue that shows how its use gives rise to justification that is genuinely epistemic in nature. Briefly, nothing short of an epistemological grounding of the virtues in relation to truth is required for them to be able to provide epistemic objectivity in a robust sense.

My own preferred account of the connection between the virtues and truth is a form of reliabilist epistemology. It is a modified version of Laudan's normative naturalist metamethodology, which places the normative naturalist metamethodology in a scientific realist framework. Combining normative naturalism with the realist idea that truth is an aim of science that may be rationally pursued transforms it into a form of reliabilism. In particular, it becomes a form of method reliabilism on which the theoretical virtues are conceived as reliable means of arriving at the realist aim of truth. The virtues are understood instrumentally, as tools of inquiry. As such, they are means for the pursuit of epistemic ends. The relation between epistemic means and ends is not a conceptual one investigated by a priori means but a contingent one, open to empirical investigation. This way of thinking of the theoretical virtues enables us to understand the question of whether a theoretical virtue is warranted as the empirical question of whether use of the virtue does in fact lead to truth. If, as a matter of empirical fact, use of a theoretical virtue does lead to truth, then acceptance of a theory that satisfies the virtue has objective epistemic warrant. It is not of course possible to immediately detect 
that use of a theoretical virtue leads to truth at the theoretical level. So I employ a metamethodological version of the realist's success argument to argue that the best explanation of the use of the theoretical virtues in producing successful scientific theories is that the virtues are in fact reliable truthconducive tools of inquiry. ${ }^{7}$

On this account, the objectivity provided by the theoretical virtues is not just minimal objectivity due to the independence and neutrality of the virtues. The objectivity provided by theoretical virtues, given that they are reliable tools of inquiry, is a robust form of objectivity. It is based on the fact that use of the theoretical virtues has a substantive bearing on truth. The theoretical virtues are, as a matter of empirical fact, truth-conducive. So the epistemic warrant that derives from the virtues has an objective basis in reality. It is an objective matter of fact that use of the virtues promotes truth.

\section{A ROLE FOR DELIBERATIVE JUDGEMENT}

The issue that I wish to discuss in this section arises because of the apparent existence of a plurality of theoretical virtues. The issue may also be framed in terms of the underdetermination of theory by data. I prefer the first way of setting the topic up because it involves fewer assumptions. However, I will canvas both ways of presenting the topic, starting with the former.

As we have seen, it is widely assumed that there are multiple theoretical virtues. Moreover, there is no established ranking of the virtues that assigns them an order of precedence. It is entirely possible that a single theory may unequivocally exemplify all relevant virtues to a significantly greater extent than all competing theories. Where this occurs, the virtues uniquely identify that theory as the best among the competing theories. However, as was famously pointed out by Kuhn (1977), different theories may exemplify different virtues. A theory may be more empirically accurate than a simpler or more coherent competitor. A theory may explain a broad range of disparate phenomena while a rival theory makes more precise predictions, or correctly predicts surprising, previously unobserved phenomena.

Where competing theories differentially satisfy the theoretical virtues, no single theory is uniquely selected by the virtues. In such a situation, the virtues are unable to determine choice of theory. How, then, is the choice to be made? Assuming that a choice is to be made as to whether to accept a theory,

7 I here summarize the naturalistic realist approach to the warrant of methodological norms that I have developed in earlier work (see, e.g., Sankey 2000, 2002). 
it is necessary to decide which of the virtues is most significant in the particular context, and therefore which virtue or virtues is to be accorded the greatest weight. ${ }^{8}$ Such a decision cannot be determined by the virtues themselves, since they are unranked. Hence, the scientist who makes the decision must form a judgement in which they weigh up the competing virtues in order to determine which virtue is to be accorded greatest importance. Such judgement is an act or process of deliberation that requires the scientist to make decisions about the relevance, importance, and comparative significance of the different theoretical virtues. The worry, as we shall see in the next section, is that such deliberative judgement may not be subject to objective constraint.

The need for scientists to exercise a capacity for deliberative judgement arises, as we have just seen, from the failure of multiple theoretical virtues to uniquely determine choice of theory. There is a further way to formulate the problem, which trades on the possibility of underdetermination of theory by data.

The problem arises as follows. Let us suppose that there may be empirically equivalent theories. That is, there may be theories that are equally supported by all of the available empirical data. ${ }^{9}$ On the assumption that there is no readily available empirical evidence to decide the issue in the manner of a crucial test, the choice between such theories may not be made on empirical grounds. How, then, is the choice to be made? It can only be made on a nonempirical basis. It is at this stage that appeal may be made to non-empirical criteria such as simplicity, coherence, unity, or elegance. But, since theories might exemplify the non-empirical virtues to varying degrees, and there is no established rank-order of the non-empirical virtues, we arrive at a similar position to that which arose due to the multiplicity of the virtues. Namely,

\footnotetext{
${ }^{8}$ Note that I do not assume that a choice must necessarily be made as to which theory to accept. It is possible to suspend judgement until further deciding evidence is available. Also, as Laudan points out, there are different cognitive modalities that scientists may adopt towards theories ranging from entertainment and pursuit at one extreme, to belief or acceptance at another (Laudan 1977).

9 The form of underdetermination indicated here is a weak form of underdetermination sometimes known as transient underdetermination. There are, of course, further forms of underdetermination that may be distinguished. For example, there is the purportedly strong form of underdetermination, which involves underdetermination of theory by all possible evidence. There is also the so-called Duhem-Quine thesis, which turns on holistic considerations, such that no empirical counter-instance constitutes a decisive refutation of a theory, since a theory is always tested in conjunction with a range of auxiliary hypotheses that may also be impugned by the negative outcome of a test. Distinctions between various forms of underdetermination have no apparent bearing on the present point.
} 
scientists must make a judgement as to which non-empirical virtues are to be accorded greatest weight. We have once again a situation in which a judgement must be made due to lack of determination by the theoretical virtues.

There is a tendency, especially in the literature relating to the virtuetheoretic reading of Duhem's notion of good sense, to favour this second way of framing the issue. ${ }^{10}$ However, I prefer the former way of presenting the problem. It is conceptually simpler. It makes fewer assumptions. It requires no assumptions about underdetermination and empirically equivalent theories that some may find questionable. In short, it carries less philosophical baggage.

\section{VIRTUOUS JUDGEMENT}

In section 4, we have seen that, due to the multiplicity of virtues, a role must be played by deliberative judgement in scientific theory-appraisal. A judgement is required in order to determine the relevance, significance, and relative importance to be accorded to the various theoretical virtues. Because they are unranked, this is not something that can be read off the virtues themselves. Instead, the scientist must exercise their own judgement in reflecting upon the range of virtues satisfied by competing theories. The decision to select one out of a field of competing theories is, therefore, based on the scientist's assessment of the comparative importance of the virtues possessed by the theories under consideration.

The role that judgement plays in theory-appraisal raises the prospect of subjective elements entering into theory-choice. For, if the scientist's judgement is not determined by the theoretical virtues, the judgement itself appears not to be subject to the constraint of objective criteria. Does this then mean that anything goes? Is theory-choice simply a matter of subjective, personal taste not open to critical scrutiny on the basis of independent standards? 11

${ }^{10}$ No doubt, the reason for the emphasis on underdetermination has to do with the holistic context in which Duhem appeals to the notion of good sense. As Abrol Fairweather puts it, the "success condition for good sense is to break the empirical stalemate" (2012: 142). Against those who appeal to theoretical virtues as a way to determine choice between empirically equivalent theories, Ivanova (2014) argues that the theoretical virtues fail to determine such choice.

${ }^{11}$ On Kuhn's analysis of such choice, there is a subjective element that is not determined by the values that he takes to provide the "shared basis of theory-choice" (1977: 322). But he denies that the subjective element makes theory-choice a matter of inscrutable personal taste. The scientist must be willing and able to explain the basis of their choice. 
It is at this juncture that the epistemic virtues described by virtue epistemology take on special relevance. I wish to suggest that the deliberative judgement made by scientists in the context of theory-choice is subject to objective constraint. The constraint is due to the epistemic virtues, which are, as we have previously seen, properties of the scientists themselves rather than properties of the theories that scientists appraise on the basis of the theoretical virtues. In the context of theory-choice, the scientist must reflect upon the manner in which competing theories satisfy the applicable theoretical virtues. The cognitive act of deliberating upon the relevance, significance, and relative importance of the theoretical virtues when applied to the competing theories may be informed and guided by the epistemic virtues of the scientist. The judgement that the scientist arrives at in determining the superiority of one of the competing theories is a judgement that may itself be a virtuous one. The way in which the epistemic virtues enter into the scientist's judgement may itself provide a further objective basis for the scientist's decision that is additional to that provided by the theoretical virtues themselves. The scientist's judgement is not unconstrained. It is subject to the objective constraint provided by the epistemic virtues.

An impressive range of epistemic virtues has been identified. ${ }^{12}$ But one of the most insightful discussions remains Stump's virtue-theoretic analysis of Duhem's idea of good sense. Stump draws attention to what he describes as Duhem's "image of the scientist as impartial judge" (2007: 151). In the appraisal of competing theories, as well as in the resulting choice of theory, the scientist is in effect cast in a role like that of a judge making a decision in relation to a legal matter. In order to fulfill that arbitrative role in an appropriate manner, it is necessary for the scientist to adopt an attitude of detached neutrality with respect to personal interests and theoretical commitments. In appropriately performing the role of impartial judge, the scientist behaves in a virtuous way. The virtue involved in performing as an impartial judge is not just a virtue that is cognitive in nature. It has a moral dimension as well. In addition, the virtuous exercise of good sense employs a capacity to arrive at a reasoned decision in the absence of clear-cut rules that might determine the outcome of the decision.

The key elements required of the scientist as judge may be found in the following passage from Duhem's book, The Aim and Structure of Physical Theory:

${ }^{12}$ In their summary of the literature on the topic, Paternotte and Ivanova provide a list of virtues that have been identified by commentators: open-mindedness, intellectual courage, intellectual sobriety, intellectual humility, faithfulness, integrity, disinterestedness, honesty, and impartiality (2017: 1791-1792). They also discuss the role played by intellectual vices in the history of science. I will have nothing to say here about the vices. 
nothing contributes more to entangle good sense and to disturb its insight than passions and interests. Therefore, nothing will delay the decision which should determine a fortunate reform in a physical theory more than the vanity which makes a physicist too indulgent towards his own system and too severe toward the system of another. We are thus led to the conclusion so clearly expressed by Claude Bernard: The sound experimental criticism of a hypothesis is subordinated to certain moral conditions; in order to estimate correctly the agreement of a physical theory with the facts, it is not enough to be a good mathematician and skillful experimenter; one must also be an impartial and faithful judge. (Duhem 1954: 218)

For Duhem, a scientist's "passions and interests" may undermine and detract from good sense. They may dispose the scientist to the "vanity" of being "too indulgent" towards their own theory while being "too severe" toward theories held by others. Rather than succumb to "passions and interests," and fall prey to such "vanity," the scientist must act as an "impartial and faithful judge."

The primary virtue involved here is the virtue of impartiality. In exercising the virtue of impartiality, the scientist forms a judgement in a neutral and detached manner. They do not unduly or unfairly take sides in relation to competing theories. Their judgement is not biased in favour of a preferred theory. With regard to the problem raised by the multiplicity of theoretical virtues, a key role played by impartiality is to ensure that relevant theoretical virtues are recognized and correctly applied. Where a theory is supported by empirical evidence, the scientist as impartial judge recognizes the existence of the evidence and accords it due weight. Where competing theories exemplify the same virtues to varying degrees, the impartial scientist recognizes the respects in which the theories satisfy those virtues. If it is possible to reach a decision based on these considerations, the impartial scientist arrives at a judicious determination of which theory is to be favoured on balance, if one theory is indeed to be favoured on balance.

Duhem's idea of the scientist as impartial judge provides an example of how an epistemic virtue such as impartiality may enter into the process of deliberative judgement. Other epistemic virtues, such as open-mindedness or intellectual honesty, may also be involved in the process. My suggestion is that appropriate activation of epistemic virtues contributes a further element to the objectivity of the decision-making process. Their involvement in the process serves to ensure that the theoretical virtues are rigorously and correctly applied. The scientist whose judgement is appropriately guided by the epistemic virtues is one whose deliberations are honestly and conscientiously conducted. Their judgement is based solely on appropriate considerations of an epistemically relevant kind rather than being subject to the influence of personal interest, political ideology, or other forms of bias. There is no guarantee, of course, that the outcome of the deliberation will be adoption of a 
true or even maximally warranted theory, since the judgement is a fallible one. Nor is there any guarantee that all scientists will arrive at the same outcome. It is simply a matter of ensuring that due weight is accorded to the various applicable theoretical virtues, and that the decision is not subject to the influence of inappropriate factors such as bias or personal interest. Such virtuous judgement, I wish to suggest, contributes significantly to the objectivity of the decision-making process.

\section{THE PRIMACY OF THE THEORETICAL VIRTUES}

We have now seen two sources for the epistemic objectivity of science. On the one hand, provided that theoretical virtues reliably promote truth, rather than merely being independent factors, they constitute a robust objective basis for scientists' adoption of theory. On the other hand, the epistemic virtues exemplified by individual scientists insert an element of objectivity into the judgement by means of which scientists determine the relevance and significance of theoretical virtues.

What is the relationship between these two sources of objectivity? What I wish to suggest is that the theoretical virtues possessed by theories are the primary locus of epistemic objectivity. If a theory fails to satisfy relevant theoretical virtues, or fails to satisfy the virtues as well as competitors, there is simply no objective basis for acceptance of the theory. If, for example, a theory is not supported by empirical evidence and fails to display such key virtues as coherence, simplicity, or breadth, it is difficult to see on what basis the theory might be accepted. It is, in short, a necessary condition for the acceptability of a theory that it satisfies relevant theoretical virtues. Indeed, it is necessary that the theory satisfy the virtues to a greater extent than alternative theories that also satisfy the virtues.

Given the apparent primacy of the theoretical virtues, I suggest that the epistemic virtues, which inform scientists' judgement of the relevance and significance of the theoretical virtues, must play a role that is secondary to that of the theoretical virtues. Whereas the theoretical virtues govern the objective acceptability of a theory, the epistemic virtues determine whether an individual scientist's application of those virtues has an objective basis. But, if the theoretical virtues play a primary role with respect to the epistemic objectivity of science, one might very well wonder whether there is any need for the epistemic virtues of individual scientists in the first place. Given that the theoretical virtues provide an objective basis for scientific theory-acceptance, 
what difference does it make whether an individual scientist's judgement is appropriately guided by the epistemic virtues?

Here an important lesson may be gleaned from the literature on process reliabilism. In order to show that a role must be played in theory-appraisal by the epistemic virtues, I wish to make a point that is analogous to the point made by Keith Lehrer in his example of Mr. Truetemp (Lehrer 1990: 163-164). Lehrer describes the case of Mr. Truetemp, who has, unbeknownst to himself, a device called a Tempucomp that has been surgically implanted in his head. The device is a highly accurate thermometer that interacts computationally with Truetemp's brain in a very specific way. Whatever the temperature in fact is, the Tempucomp makes Truetemp consciously hold the belief that that is what the temperature is. If the temperature is $40^{\circ}$ Celsius, Truetemp believes that it is $40^{\circ}$ Celsius. If it is $20^{\circ}$ Celsius, Truetemp believes that it is $20^{\circ}$ Celsius. In other words, the process whereby the Tempucomp produces temperature beliefs in the mind of Truetemp is a reliable belief-forming process. In fact, it is a perfectly reliable process. As such, for the process reliabilist, Truetemp's reliably formed true temperature beliefs must surely constitute justified beliefs about the temperature. Indeed, given that the beliefs are both true and justified, they must constitute knowledge about the temperature. But Truetemp has no awareness whatsoever of the basis of his temperature beliefs. Worse, as a side-effect of the surgery in which the Tempucomp was implanted, Truetemp does not even reflect upon the fact that he has these beliefs or upon whether they are true or reliably formed. Truetemp is, as Lehrer says, "only slightly puzzled about why he thinks so obsessively about the temperature" (1990: 163-164).

The standard reaction to the Truetemp case is that there is something lacking in relation to Truetemp's beliefs about the temperature. Truetemp cannot know what the temperature is, or indeed have justified beliefs about the temperature, if he is completely oblivious of the basis of said beliefs. For Truetemp's beliefs about the temperature either to be justified or to form knowledge, he must at the very least be aware of the basis for the beliefs. The fact that he has no awareness whatsoever of why he holds the beliefs undermines the reliabilist thought that Truetemp has justified beliefs about the temperature that derive from the reliable belief-formation process produced by the Tempucomp. ${ }^{13}$

${ }^{13}$ I here employ the Truetemp example as a way to illustrate the need to grant a role to epistemic virtues in the context of theory-appraisal. But it is worth mentioning that examples such as the Truetemp case constitute problems for process reliabilism that virtue-theoretic approaches may be able to avoid. The Tempucomp-based belief-formation process can hardly be deemed a virtuous one. Examples such as these are part of the reason that some 
An analogous thought, I suggest, applies to the case of the theoretical virtues. Without going so far as to imagine a full-blown Truetemp case, let us suppose that a scientist accepts a theory that maximally satisfies all relevant theoretical virtues. But the scientist has no awareness of the fact that the theory satisfies the virtues. Nor does the scientist reflect upon the fact that the theory satisfies the virtues as the basis of their acceptance of the theory. Surely, in a manner that is analogous to the Truetemp case, there is something fundamentally lacking in the scientist's acceptance of the theory. The theory itself may well have a high degree of epistemic warrant due to satisfaction of the theoretical virtues. But the scientist's acceptance of the theory that satisfies those virtues has no basis whatsoever. The scientist must, at the very least, be aware that the theory satisfies the theoretical virtues if they are to be justified in the acceptance of the theory. Though there is an objective basis for acceptance of the theory, in not being aware of that basis the scientist's own acceptance of the theory is without objective basis.

On the assumption that there is a close analogy between Lehrer's Truetemp case and the case of the scientist who accepts a warranted theory without awareness of the basis of the warrant, we may suggest the following. At the very least, a scientist must be aware of the theoretical virtues, of the fact that a theory satisfies or fails to satisfy the virtues, must reflect upon the virtues and the satisfaction of the virtues by the theory, and must decide whether or not to accept the theory on the basis of the reflective consideration of the extent to which the theory satisfies the virtues. Unless the scientist engages in such reflection, there can be no sense in which the scientist's acceptance of the theory that is warranted by the theoretical virtues has any rational, or, indeed, objective basis.

The Truetemp-style case enables us to see that a role must be played by a scientist's reflective awareness of the theoretical virtues in theory-appraisal and choice. What I wish to suggest is that it is at this juncture in the decisionmaking process that the epistemic virtues play a vital role. In determining which theory best satisfies the relevant theoretical virtues, a scientist must consider the extent to which alternative theories satisfy the theoretical virtues. In the course of such consideration, the scientist must proceed in a way that exemplifies the epistemic virtues. They must, for example, proceed in the manner of Duhem's impartial scientist-judge, setting aside personal interest and granting due weight to the empirical and non-empirical virtues displayed by the competing theories. The scientist whose conscientious reflection upon

philosophers have come to favour virtue-theoretic approaches over earlier forms of process reliabilism. 
the relevance and significance of the theoretical virtues leads them to a fair and judicious assessment of the merits of the theories is one whose deliberation is conducted in a way that is appropriately informed by the epistemic virtues. The judgement that they reach on the basis of such conscientious application of the theoretical virtues is a virtuous judgement. In this way, the epistemic virtues contribute substantively to the objectivity of the decisionmaking process.

While I maintain that the epistemic virtues contribute substantively to the objectivity of theory-appraisal and choice, I wish nevertheless to suggest that they play a secondary role to the theoretical virtues. The reason is that the acceptability or otherwise of a theory is governed by the theoretical virtues, since it is their role to promote and deliver truth or approximate truth at the level of theories. Given their role in the pursuit of truth, the theoretical virtues play the primary role in establishing the epistemic objectivity of science. However, the theoretical virtues need to be rigorously and conscientiously applied. This is where exercise of the epistemic virtues is able to contribute substantively to the objectivity of science by ensuring that the theoretical virtues are appropriately applied, and their significance is fairly assessed. But, while the epistemic virtues therefore play a vital role in the deliberative process, their role is subordinate to that of the theoretical virtues. For without the theoretical virtues, there would be no basis for acceptance of a theory in the first place. It is the theoretical virtues that determine the quality of the theory.

\section{CONCLUSION}

In this paper, I have explored the relationship between theoretical and epistemic virtues with respect to the epistemic objectivity of science. I have argued that the theoretical virtues possessed by theories are the primary locus of the epistemic objectivity of science. Because the theoretical virtues are not merely independent factors, but genuinely truth-conducive tools of inquiry, they provide scientists with an objective basis for theory-acceptance that is robust rather than minimal in character. The epistemic virtues which individual scientists possess, and which may inform their deliberations relating to the application of the theoretical virtues, play a role that is subordinate to that of the theoretical virtues with respect to the objectivity of science. Nevertheless, the epistemic virtues contribute substantively to the epistemic objectivity of science, since they promote the rigorous application of the theoretical virtues. 
I have not entered into the question of which form of virtue epistemology most adequately captures the objective elements of science. That is a question for future work. What I hope to have shown is that the epistemic virtues of individual scientists may serve to enhance the robust objective basis for theory acceptance that is provided by the theoretical virtues. Nor have I entered into the question of the social aspects of scientific objectivity. It seems clear that there are a number of ways in which collaborative aspects of scientific inquiry may contribute to the objectivity provided by the exercise of the epistemic virtues. That, too, must wait for future work.

\section{BIBLIOGRAPHY}

Axtell G. (1997), "Recent Work on Virtue Epistemology," American Philosophical Quarterly 34(1), 1-26.

Douglas H. (2004), "The Irreducible Complexity of Objectivity," Synthese 138(3), 453-473. https://doi.org/10.1023/B:SYNT.ooooo16451.18182.91

Douglas H. (2013), "The Value of Cognitive Values," Philosophy of Science 80, 796-806. https://doi.org/10.1086/673716

Duhem P. (1954), The Aim and Structure of Physical Theory, tr. P. Weiner, Princeton: Princeton University Press [first published 1906].

Fairweather A. (2012), "The Epistemic Value of Good Sense," Studies in History and Philosophy of Science 43, 139-146. https://doi.org/10.1016/j.shpsa.2011.11.003

Ivanova M. (2010), "Pierre Duhem's Good Sense as a Guide to Theory Choice," Studies in History and Philosophy of Science 51, 58-64. https://doi.org/10.1016/j.shpsa.2009. 12.009

Ivanova M. (2011), “'Good Sense' in Context: A Response to Kidd," Studies in History and Philosophy of Science 42, 610-612. https://doi.org/10.1016/j.shpsa.2011.09.006

Ivanova M. (2014), "Is There a Place for Epistemic Virtues in Theory Choice?" [in:] Virtue Epistemology Naturalized: Bridges between Virtue Epistemology and Philosophy of Science, A. Fairweather (ed.), Cham: Springer International Publishing, 207-226. https://doi.org/10.1007/978-3-319-04672-3_13

Kidd I. (2011), "Pierre Duhem's Epistemic Aims and the Intellectual Virtue of Humility: A Reply to Ivanova," Studies in History and Philosophy of Science 42, 185-189. https://doi.org/10.1016/j.shpsa.2010.11.007

Kuhn T. S. (1977), “Objectivity, Value Judgment and Theory Choice” [in:] T. S. Kuhn, The Essential Tension, Chicago: University of Chicago Press, 320-329.

Laudan L. (1977), Progress and its Problems, Berkeley: University of California Press.

Laudan L. (2004), "The Epistemic, the Cognitive, and the Social" [in:] Science, Values, and Objectivity, P. Machamer, G. Wolters (eds.), Pittsburgh: University of Pittsburgh Press, 14-23. https://doi.org/10.2307/j.ctt5vkg7t.5

Lehrer K. (1990), Introduction to the Theory of Knowledge, London: Routledge.

McMullin E. (2008), "The Virtues of a Good Theory" [in:] The Routledge Companion to Philosophy of Science, S. Psillos, M. Curd (eds.), London-New York: Routledge, 498-508. 
Paternotte C., Ivanova M. (2017), "Virtues and Vices in Scientific Practice," Synthese 194, 1787-1807. https://doi.org/10.1007/s11229-016-1023-2

Sankey H. (2000), "Methodological Pluralism, Normative Naturalism and the Realist Aim of Science” [in:] R. Nola, H. Sankey (eds.), After Popper, Kuhn and Feyerabend: Recent Issues in Theories of Scientific Method, Dordrecht: Kluwer Academic Publishers, 211-229. https://doi.org/10.1007/978-94-011-3935-9_8

Sankey H. (2002), "Realism, Method and Truth" [in:] The Problem of Realism, M. Marsonet (ed.), Aldershot: Ashgate, 64-81. https://doi.org/10.4324/9781315185507-4

Sankey H. (forthcoming), "Realism and the Epistemic Objectivity of Science," Kriterion Journal of Philosophy.

Stump D. (2007), "Pierre Duhem's Virtue Epistemology," Studies in History and Philosophy of Science 38, 149-159. https://doi.org/10.1016/j.shpsa.2006.12.010

Tulodziecki D. (2014), "Epistemic Virtues and the Success of Science" [in:] Virtue Epistemology Naturalized: Bridges Between Virtue Epistemology and Philosophy of Science, A. Fairweather (ed.), Cham: Springer International Publishing, 247-268. https://doi.org/ 10.1007/978-3-319-04672-3_15

van Fraassen B. (1980), The Scientific Image, Oxford: Oxford University Press. https:// doi.org/10.1093/0198244274.001.0001 